\title{
Creativity among psychosis prone individuals: Hypomanic and Highly Schizotypal Evidence for confirmation the inverted- $U$ relationship between creativity and psychopathology
}

\author{
Samad Hamidi ${ }^{1}$, Abbas Rohani ${ }^{2}$, Somaye Tahazade ${ }^{3}$, Younes Yousefi ${ }^{3}$, Fayegh Yousefi ${ }^{4}$ \\ 1- M.A in Clinical Psychology, Afra Psychological Counseling Center, Sanandaj, Iran (Corresponding Author). \\ E-mail: samadhamidi@gmail.com \\ 2- Assistance Professor, Department of Psychology, Islamic Azad University Mobarakeh Branch, Mobarakeh, Iran. \\ 3- M.A in Clinical Psychology, Afra Psychological Counseling Center, Sanandaj, Iran. \\ 4- Associate Professor, Spiritual Health Research Center, Research Institute for Health Development, Kurdistan \\ University of Medical Sciences, Sanandaj, Iran.
}

Received: 02/09/2019

Accepted: 02/12/2019

\begin{abstract}
Introduction: Creativity is a multi-dimensional structure measured by a variety at methods.
\end{abstract}

Aim: This study has been done with the aim of comparing creativity among hypomanic and highly schizotypal with normal individuals.

Method: The method of this research is comparative causative research and statistical community consisted of undergraduate of Tabriz University in the academic year of 2017-2018. The sample size was 1570 student were selected Using randomized cluster sampling and completed schizotypy personality questionnaire (Raine \& et al 1994) and Hypomania Checklist (Forty \& et al 2010) and were divided into 3 groups of normal, highly schizotypal and hypomanic, afterward they completed Abedi Creativity Test (Daemi and Moghimi 2004), Torrance Tests of Creative Thinking Verbal Form B (Torrance, 1988) and drawing with Latin letters (made questionnaire). The obtained data was analyzed using descriptive statistics and ANOVA.

Results: The results showed that hypomania and highly schizotypy groups (psychosis-prone individuals) obtained significantly higher scores than normal groups in creativity assessment tools. $(\mathrm{P}<0.05)$.

Conclusion: Schizotypy and Hypomania are related to creativity and the results of this study can be used as on evidence to confirm the relationship between inverted-U creativity and psychopathology.

Keywords: Creativeness, Psychopathology, Psychosis prone, Hypomania, Schizotypal

How to cite this article : Hamidi S, Rohani A, Tahazade S, Yousefi Y, Yousefi F. Creativity among psychosis prone individuals: Hypomanic and Highly Schizotypal. Evidence for confirmation the inverted-U relationship between creativity and psychopathology. Shenakht Journal of Psychology and Psychiatry. 2020; 6 (6): 101-112 .URL: http://shenakht.muk.ac.ir/article-1-534-fa.pdf

Copyright (๑) 2018 the Author (s). Published by Kurdistan University of Medical Sciences. This is an open access article distributed under the terms of the Creative Commons Attribution-Non Commercial License 4.0 (CCBY-NC), where it is permissible to download, share, remix, transform, and buildup the work provided it is properly cited. The work cannot be used commercially without permission from the journal. 


\section{خلاقيت در افراد مستعد سايكوز: هاييومانيك و اسكيزوتاييى بالا شواهدى در تأييد ارتباط U وارونه خلاقيت و آسيبشناسى روانى}

صمد حميدى'، عباس روحانى '، سميه طه زاده"، يونس يوسفى"، فايق يوسفى ا. كارشناس ارشد روانشناسى بالينى، مركز مشاوره و خدمات روانشناختى افرا، سندج، ايران (مولف مسئول). ايميل: samadhamidi@gmail.com

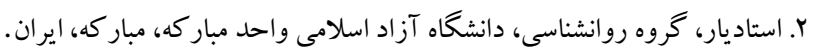

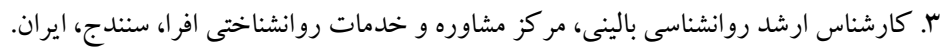

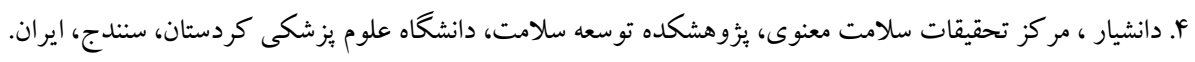
تحصيلى و

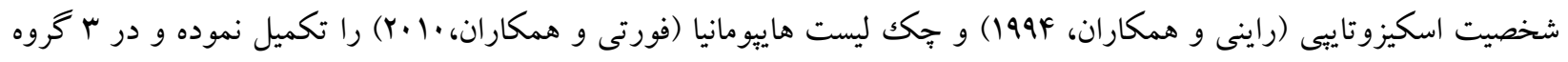

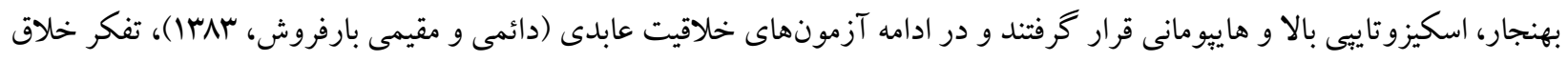
كلامى تورنس فرم ب (تورنس، روش آمارى توصيفى و آنوا تجزيه و تحليل شد. يافتها: يافتها نشان مىدهد كه گروه هاييومانى و اسكيزوتاييى بالا (افراد مستعد سايكوز) در ابزارهاى سنجش خلاقيت نمرات

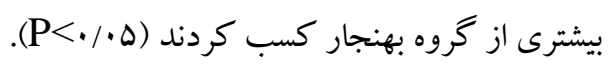

نتيجه كيرى: اسكيزوتاييى و هييومانى با خلاقيت ارتباط دارند و نتايج اين بزوهش مىتواند شاهدى براى تائيد ارتباط U وارونه خلاقيت و آسيب شناسى روانى باشد. كليد وازهها: خلاقيت، آسيب شناسى روانى، استعداد سايكوز، هييومانى، اسكيزو تاييال 
معنى دارى دارد (آيزينكک، ه9901). تعدادى از يثزوهشها رابطه خلاقيت و آسيبشناسى روانى را در مردان قوىتر يافتند (مارتين بروفا و كوربالان، 19 1.). اكرجه خلاقيت و آسيبشناسى روانى ارتباط نزديكى با هم دارند، بعضى از محققان ارتباط مثبت و معنىدارى بين خلاقيت و و و سلامت روانى يافتند (دورنبر كر '، 1999). رابطه خلاقيت

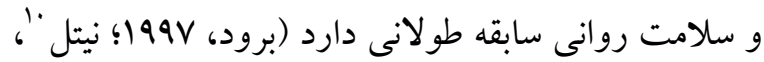

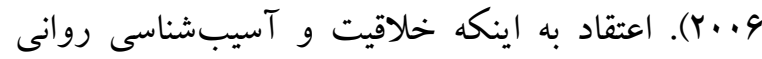

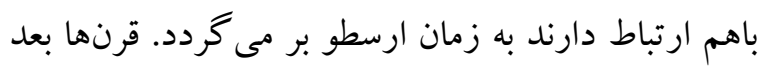
روان شناسان و روان بزشكان اين باور را گسترش دادند. در مناقشههاى كنونى در مورد ارتباط خلاقيت با آسيبشناسى روانى از يك طرف ارتباط بين اختلالات طيف

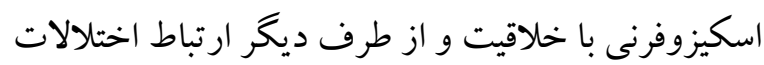
عاطفى (افسردگى -شيدايى ") با خلاقيت مطرح مىشود.

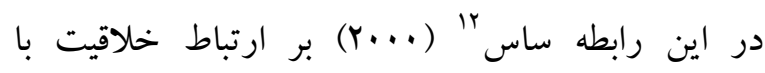
اختلالات طيف اسكيزوفرنى تأكيد مى كند و جاميسون

(Y... (Y. بر ارتباط خلاقيت با اختلالات طيف دوقطبى ".

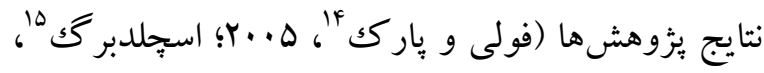

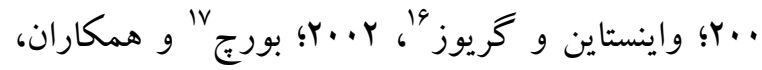

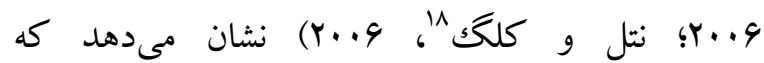
اسكيزوتايبى 19 با خلاقيت ارتباط مثبتى دارد. اخرجهه تحقيقات صورت گرفته در جمعيت عمومى بيشتر بر اسكيزوتايبى و اختلالات طيف اسكيزوفرنى تأكيد داشتهاند. اختلال دوقطبى مدت زمان زيادى است كه

${ }^{8}$ - Eysenck

9 - Durrenberger

${ }^{10}$ - Nettle

11- Manic depression

${ }^{12}$ - Sass

${ }^{13}$ - Bipolar spectrum

${ }^{14}$ - Folley\& Park

${ }^{15}$ - Schuldberg

${ }^{16}$ - Weinstein\& Graves

${ }^{17}$ - Burch

${ }^{18}$ - Clegg

${ }^{19}$ - Schizotypy
مقدمه خلاقيت' سازهاى جِند بعدى است كه توسط ابزارهاى گوناگونى اندازه گيرى مىشود. براى خلاقيت تعاريف

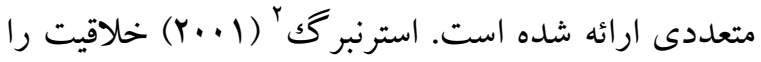
توانايى ايجاد انديشهاى نو در سطح عالى مىداند كه آميزهاى از توان نو آورى، انعطاف يذيرى و حساسيت در برابر باورهاى موجود است و به فرد اين توانايى را مىدهد كه همراه با انديشه منطقى و خردمندانه به يافتهاى ديخرى بينديشد تا دستاوردهاى سودمند براى او و و

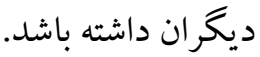
نتايج يُزوهشها حاكى از آن است كه خلاقيت با

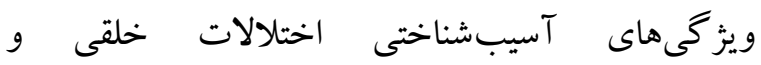
روانيريشى َارتباط دارد. شواهد تجربى و بالينى نشان مىدهد كه ميزان و شدت علائم آسيبشناسى روانى در افراد خلاق بيشتر از جمعيت عمومى است (جاميسون؛ (1919). همجِنين نتايج تحقيقاتى كه در اين زمينه صورت كرفته است نشان مىدهد كه افرادى كه خلاقيت بالايى

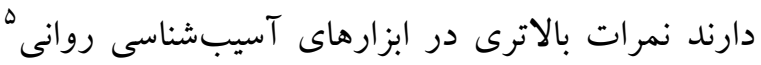
كسب مى كنند (آندرسون؛' 91VV) روانى در افرادى ديده شده است كه مشاغلى دارند كه به سطوح بالاى خلاقيت نياز دارد، ماند هنرمندان و

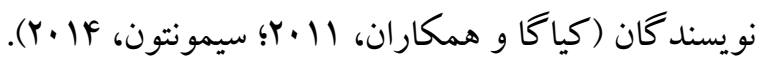
علاوه بر اين در خويشاوندان افراد اسكيزوفرنى و ديخر اختلالات، خلاقيت بيشتر از افراد عادى ديده مىشود (برود V، 199V) و خلاقيت با روانرنجورى ارتباط مثبت و

\footnotetext{
1 - Creativity

2- Sternberg

3 - Psychotic

4- Jamison

5 - Psychopathology

6 - Andreasen

7. Brod
} 
است كه ويز گىهاى سايكوتيكك به عنوان طيف صفات شخصيتى در جمعيت عمومى ديده مىشود. استفاده از نمونهاى اسكيزوتاييى و هاييومانى فرصت مناسبى براى مطالعه شاخصهاى زيستى و شناختى آسيبپيذير براى اسكيزوفرنى و دوقطبى بدون مداخله اثرات بلندمدت بسترى در بيمارستان و مصرف دارو را فراهم مى آورد؛ بنابراين هدف از يثوهش حاضر مقايسه خلاقيت در افراد هاييومانيك، اسكيزوتايبى بالا و افراد

بهنجار است.

روش

يزوهش حاضر توصيفى از نوع على - مقايسهاى است. جامعه آمارى يزٔوهش حاضر را كليهى دانشجويان دوره كارشناسى تشكيل دادند كه در دانشگاه تبريز مشغول به تحصيل بودند. با استفاده از روش نمونه گيرى تصادفى خوشهاى ·lDV نفر از دانشجويان دوره كارشناسى انتخاب شدند. طى اجراى وثزوهش، جهت ايجاد انخيزه مشاركت در شركت كنندهها ابتدا فرايند يزوهش براى برى آزمودنىها شرح داده شد، سيس برسشنامه شخصيت

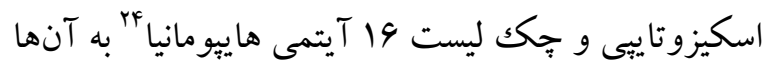
داده شد تا تكميل كنند. معيار ورود به بثزوهش نمرات بالاتر از نقطه برش ( أF) و ويايينتر از نقطه برش (YI) در يرسشنامه شخصيت اسكيزوتايبى (به عنوان افراد داراى صفت اسكيزوتاييى بالا و بايين) و نمرات بالاتر از نقطه برش (V) و يايين تر از نقطه برش (r) در جـك ليست 19 آيتمى هايِيومانيا (به عنوان افراد داراى صفت هايِومانى بالا و يايين) بود. معيار خروج عبارت بود از سابقه بيمارى روانيزشكى فعلى و قبلى و همجنين عدم حضور افراد بعد از تكميل ابزارهاى غربالگرى به منظور انجام مصاحبه

${ }^{24}$ - Hypomania Checklist
مورد توجه قرار گرفته است. در اين راستا آكيسكال (1911) طيف دوقطبى را مطرح مى كند و اظهار مى كند كه ويز كىهاى عاطفى جِون هايبومانى و سيكلوتايمى ويز كىهاى بيشمرضى هستند كه شكل خفيف اختلال

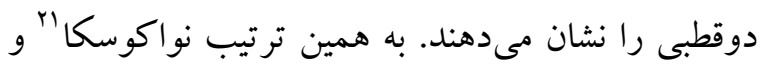

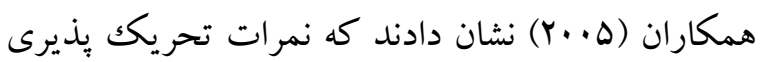
و سيكلوتايمى در شركت كنند كان دو قطبى و كروه كنترل خلاق بيشتر از افراد بهنجار است. استرونگك بَّ و

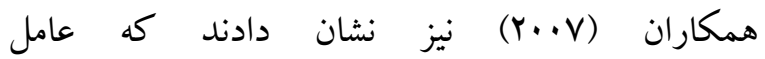
سيكلوتايمى /ديستايمى با خلاقيت ارتباط دارد. هميجين

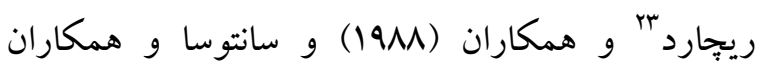
سطوح بالايى از خلاقيت را در بيماران دوقطبى (Y.VV)

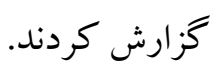
در اين راستا برود (199V) اظهار مى كند كه آسيبشناسى روانى شديد فعاليت خلاق را بازدارى مى كند. او خاطرنشان مى سازد كه خلاقيت به جاى سايكوز تمام عيار با آسيبشناسى روانى خفيف ارتباط دارد؛ بنابراين

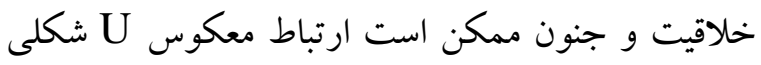
داشته باشند. به اين ترتيب در حالت آسيبشناسى روانى خفيف ميزان خلاقيت افزايش مىيابد و با شديدتر شدن آسيبشناسى روانى ميزان خلاقيت كاهش مىيابد (آكيسكال و آكيسكال 1941). نتايج تحقيقات ريبجارد و همكاران (1911) از اين ديد كاه حمايت مى كند. نتايج آنها نشان داد كه بستخان درجه يكك سالم افراد مبتلا به اختلالات روانى سطوح بالاترى از خلاقيت را نشان دادند. اين ارتباط وارونه U شكل متناظر با اين ديد كاه

\footnotetext{
${ }^{20}$ - Akiskal

${ }^{21}$ - Nowakowska

${ }^{22}$ - Strong

${ }^{23}$ - Richards
} 
غريب" 'ا عاطفهُ سطحى "r و سوءظن "rاست. عامل ها نيز

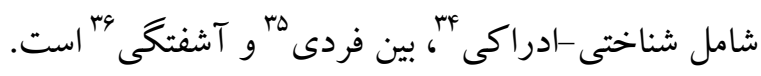
تحليل عاملى تأييدى نشان داده است كه برسشنامه

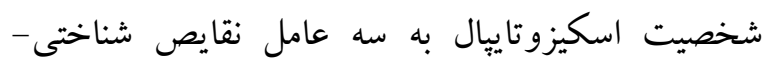
ادراكى، نقايص بين فردى و آشفتكى تقسيم مىشود

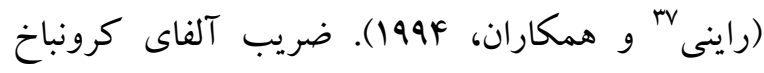

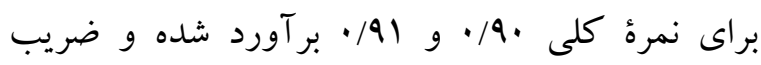

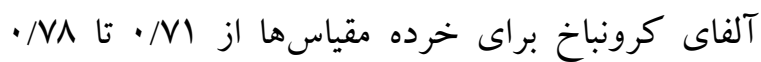

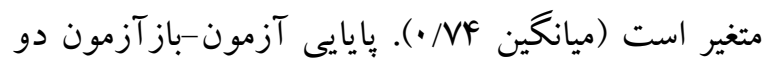

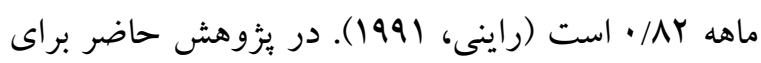
تعيين ضريب همسانى درونى از روش آلفاى كرونباخ

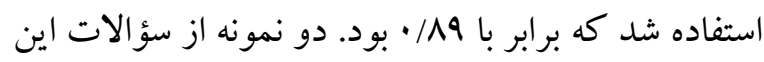
برسشنامه به شرح زير است: 1- آيا شده احساس كنيد نيرو يا فردى در اطراف شماست، حتى اكر نتوانيد آن را بينيد؟ Y - آيا شده گاهى در تبليغات، يا در ويترين مغازه ها و يا طرز قرار گرفتن اشياى دور و برتان معناى خاصى ليدي

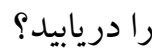

جك ليست وإ آيتمى هاييومانيا: اين جك ليست يك ابزار غربالگرى است كه براى شناسايى مؤلفهاى هاييومانيكك در بيماران مبتلا به اختلال دوقطبى و كمكك برك به متخصصين براى تمايز بين اختلال افسردگى اساسى و اختلال دوقطبى نوع I و II ساخته شده است. ضريب

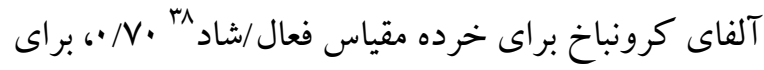
خرده مقياس تحريكك بذيرى / خطريذيرى

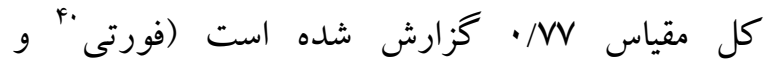

31- Odd speech

${ }^{32}$ - Constricted affect

${ }^{33}$ - Suspiciousness

${ }^{34}$ - Cognitive-Perceptual

${ }^{35}$ - Interpersonal

${ }^{36}$ - Disorganized

${ }^{37}$ - Raine

${ }^{38}$ - Active/elated

39- Irritable/risk-taking

${ }^{40}$ - Forty
بعد از دو بار ييخيرى بود. در نهايت به صورت تصادفى از

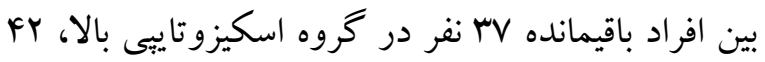
نفر در گروه هايبومانى و ·F نفر در گروه بهنجار قرار كرفتند و ابزارهاى مربوط به سنجش خلاقيت را تكميل

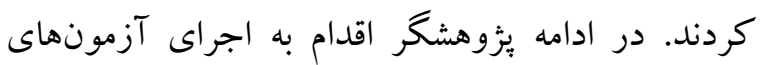
غربال گرى نموده و در مرحله بعد افرادى را كه واجد شرايط شركت در بزوهش بودند به وسيله تماس تلفنى ثبت شده در برسشنامههاى غربال رُى به مرحله بعد دعوت كردند و شركت كنندهها آزمونهاى خلاقيت را بران تكميل كردند. سبس در يكك جلسه براى افراد شركتكننده نحوه تكميل برسشنامهها و تكاليف مربوط به به به برن سنجش خلاقيت توضيح داده شد. يس از جمع آورى دادها تحليل دادها با استفاده روشهاى آمارى توصيفى سيى و استنباطى تحليل واريانس يكك طرفه (ANOVA) به

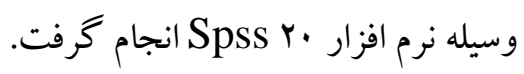

ابزار يرسشنامه ويثگحىهاى جمعيتشناختى: اين يرسشنامه محقق ساخته و به منظور تعيين مشخصات جمعيتشناختى آزمودنىها از جمله جنسيت، وضعيت تحصيلى، تحصيلات يدر و مادر و تعداد اعضاى خانواده تهيه كرديد. يرسشنامه شخصيت اسكيزوتاييال (SPQ): اين ابزار شامل VF برسش، 9 ماده و r عامل است. مادهها شامل: عقايد

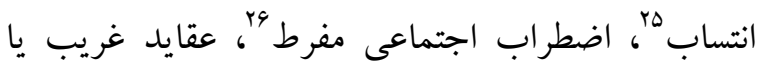

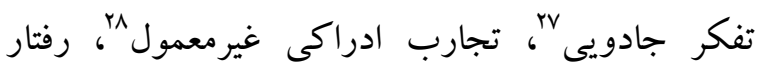

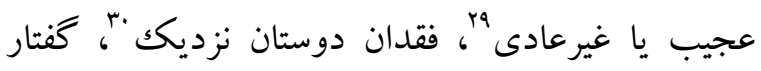

\footnotetext{
${ }^{25}$ - Idea of reference

${ }^{26}$ - Excessive social anxiety

${ }^{27}$ - Odd beliefs or magical thinking

${ }^{28}$ - Unusual perceptual experiences

${ }^{29}$ - Eccentric/odd behavior

${ }^{30}$ - No close friends
} 
ج: قطعه گم شده را ييدا مى كنم و اكر نتوانم آن را بيدا كنم، به جاى آن قطعه ديخرى مى سازم) يرسشنامه خلاقيت تورنس فرم ب: اين آزمون شامل سه قسمت تصويرسازى، تكميل تصاوير و تصويرسازى با دايرهها است كه بر اساس جهار ويز گیى اصلى تفكر واگرا يعنى سيالى، انعطاف يذيرى، بسط و ابتكار كه در مدل

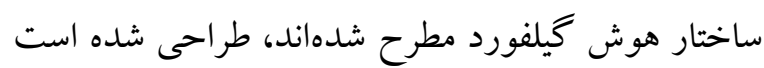

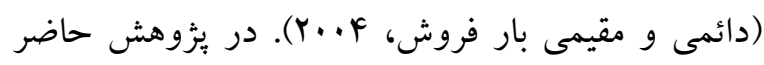
براى تعيين ضريب همسانى درونى از روش آلفاى كرونباخ استفاده شد كه برابر با ||1/ • بود. تكليف تصويرسازى با حروف لاتين: در اين روش براى محاسبه خلاقيت، ه·1 حرف لاتين (T) O O O X شر كت كنندها داده شد و از آنها خو استه شد با حروف مذكور اشكالى را كه به ذهنشان خطور مى كند، ترسيم كنند. نمره گذارى در اين آزمون بر اساس قسمت تصويرسازى با دايرهها بود و هر باسخ درست يكك نمره

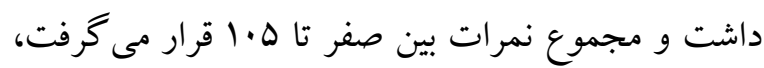
نمره ياداش نيز در اين قسمت منظور شد. وجود هر نشانهاى كه گوياى تفكر خلاق بود در ارزيابى لحاظ مى - نهى شد و اشكال مخدوش و تكرارى نمره نمى گرفتند. براى بررسى ضريب همسانى درونى از آلفاى كرونباخ استفاده شد كه برابر با 199/ • بود.

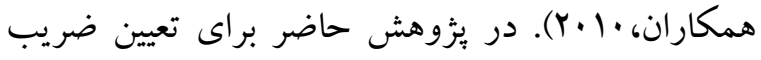
همسانى درونى از روش آلفاى كرونباخ استفاده شد كه برابر با VI/ • بود. دو نمونه از سؤالات اين يرسشنامه به شرح زير است: ا- من زياد حرف مى زنم، ب-از نظر جسمانى خيلى فعال هستم (مثلاً در ورزش) رئ. يرسشنامه خلاقيت عابلى: اين يرسشنامه شامل •4 سؤال

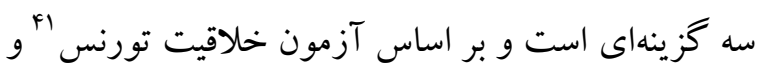

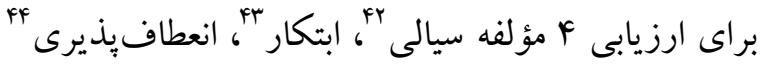

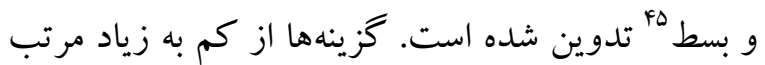
شدهاند. گزينه الف ا امتياز، گزينه ب ب امتياز و گزينه ج

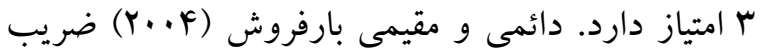
هايايى باز آزمايى خرده مقياسهاى سيالى، بسط، ابتكار و انعطاف بذيرى را به ترتيب س / •، FF/ •، كزارش كردند. در بزّوهش حاضر براى تعيين ضريب همسانى درونى از آلفاى كرونباخ استفاده شد كه براى مؤلفه هاى سيالى، ابتكار، انعطاف يذيرى و بسط به ترتيب / PA دست آمد. دو نمونه از سؤالات اين برسشنامه به شرح زير است: ا-وقتى با مسئله تازهاى روبهرو مىشويد، معمولاً

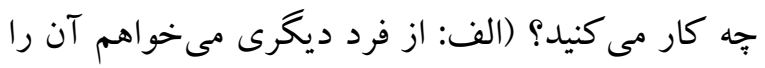
برايم حل كند. ب: سعى مى كنم با كمك فرد ديخرى، آن را حل كنم. ج: سعى مى كنم اطلاعات بيشترى به دست آورم تا بتوانم خودم آن را حل كنم). r- اكر سرگرم ساختن وسيلهاى باشيد و ناخهان دريابيد كه قطعه مهمى از آن را گم كردهايد، جهه كار مى كنيد؟ (الف: كار را متوقف مى كنم. ب: سعى مى كنم قطعه گم شده را بيدا

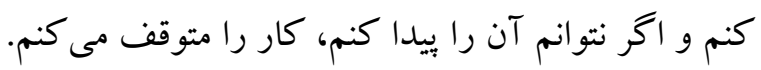

${ }^{41}$ - Torrance creativity test

42 - Fluency

43 - Originality

44 - Flexibility

45 - Elaboration 


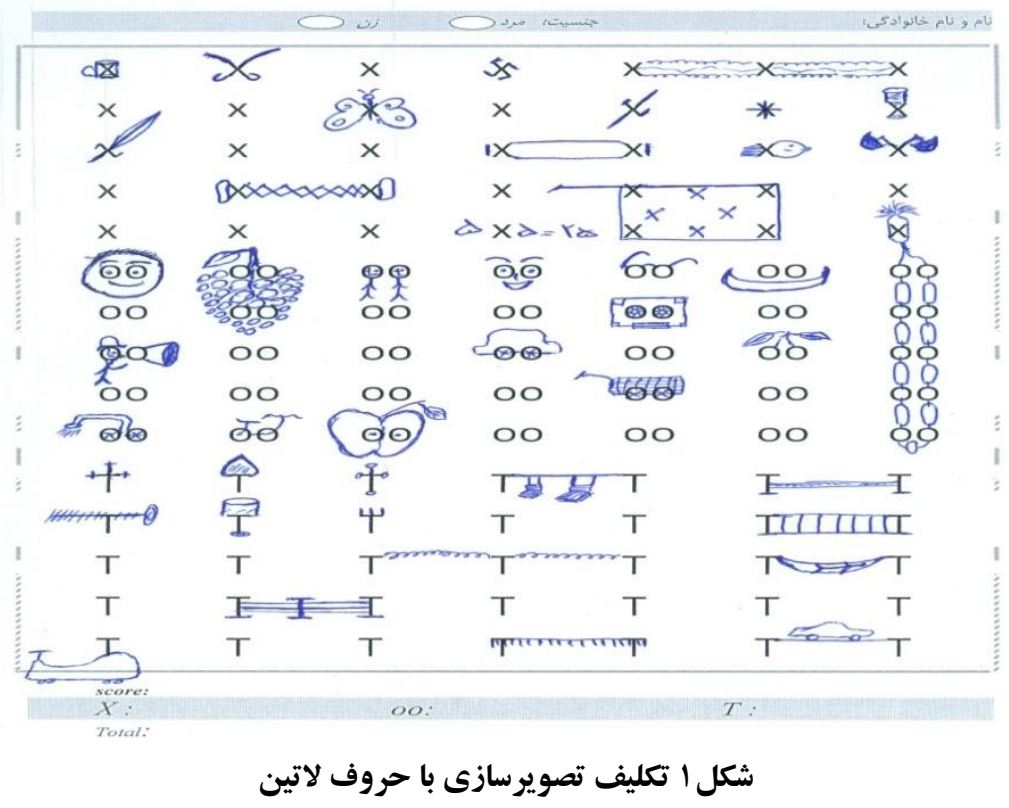

آزمون آمارى وجود دارد. براى تعيين اينكه اين تأثير

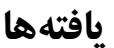

كلى در كدام گروهها وجود دارد، آزمون تحليل در اين هئوهش خلاقيت متغير مستقل و گروهها واريانس يكك طرفه (ANOVA) انجام گرفت. با توجه (هاييومانى، اسكيزوتاييى بالا و بهنجار) به عنوان متغير به معنادارى تفاوتها در متغيرهاى مورد نظر براى وابسته مطرح هستند. بر اين اساس، با توجه به وجود يك مشخص كردن دقيق تفاوتها در بين سه گروه از آزمون متغير مستقل و بيث از دو متغير وابسته، از تحليل واريانس حداقل اختلاف معنىدار استفاده شد. در جدول شماره 1 يكك طرفه به عنوان روش آمارى استفاده شد. بر اساس مشخصات جمعيتشناختى گروهها آورده شده است.

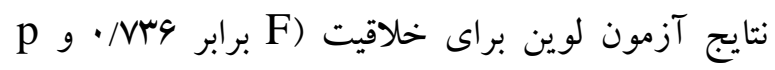
برابر NADA • بيشفرض تساوى واريانسها مورد تأييد قرار مى گيرد و مفروضهى لازم براى استفاده از اين

جدول ا شاخصهاى جمعيتشناختى هر يك از كروهها به تفكيك

\begin{tabular}{|c|c|c|c|c|}
\hline بهنجار & هايِومانى & اسكيزوتاييى بالا & & \\
\hline فراوانى (درصد) & فراوانى (درصد) & فراوانى (درصد) & & متغير \\
\hline$N=r$. & $\mathrm{N}=r r$ & $\mathrm{~N}=r v$ & & \\
\hline$(V / \Delta) r$ & $(Q / \Delta r) F$ & rו & ضعيف & وضعيت تحصيلى \\
\hline$(r V / \Delta) 10$ & $(\Delta \cdot) r_{1}$ & $(r V / \wedge \Delta) \mid F$ & متوسط & \\
\hline$(\Delta \Delta) Y r$ & $(F \cdot / F V) I V$ & $(Y V / \cdot Y))$. & خوب & \\
\hline
\end{tabular}




\begin{tabular}{|c|c|c|c|c|}
\hline & & & بـ بواد & تحصيلات يدر \\
\hline$(Y V / \Delta) \| 11$ & $(Y r / A I) 1$. & $(Y F / Y Y) q$ & زير دييلم & \\
\hline$(10) 9$ & $(19 / \cdot \Delta) \wedge$ & $(Y F / M Y) q$ & دييلم و فوق & \\
\hline r & $(Y N / \Delta V) I r$ & $(19 / Y \mu)^{9}$ & ديلم & \\
\hline$(Y Y / Q) q$ & $(19 / \cdot \Delta) \wedge$ & $(F \Delta / q \Delta) \mid V$ & ل ليسانس & \\
\hline$(I Y / \Delta) \Delta$ & rו (r./9D) & $(Y q / V F) \|$ & بالاتر & \\
\hline$(K Y / Q) I V$ & 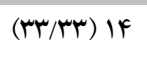 & $(Y F / Y Y) q$ & بى سو اد & تحصيلات مادر \\
\hline$(Y Y / \Delta) q$ & $(19 / 9 \mathrm{~V}) \mathrm{V}$ & - & زير دييلم & \\
\hline$(10) 9$ & $(F / V V) r$ & - & دييلم و فوق & \\
\hline$(Y V / \Delta) 11$ & $(19 / 9 \mathrm{~V}) \mathrm{V}$ & $(Y F / M Y) q$ & دييلم & \\
\hline$(I V / \Delta) V$ & 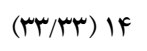 & $(Y q / V F) \|$ & ليسانس و & \\
\hline \multirow[t]{5}{*}{$(F \cdot) 19$} & $(F \Delta / Y \mu) 19$ & $(F \Delta / Q F) \mid V$ & بالاتر & \\
\hline & & & r تا بنفر & \\
\hline & & & ستا F نفر & تعداد اعضاى \\
\hline & & & F تا ها نفر & خانواده \\
\hline & & & 9نفر و بيشتر & \\
\hline
\end{tabular}

كرفتند. اكثريت افراد شر كت كننده در بزٔوهش دختران با ع) عملكرد تحصيلى متوسط و از خانو ادههاى برجمعيت نفر به بالا) بودند. در جدول شماره r نتايج يافتهاى توصيفى، آزمون تحليل واريانس يكك طرفه و آزمون حداقل اختلاف معنىدار به تفكيك كروهها آورده شده
نتايج جدول ا نشان مىدهد كه تعداد ها نفر از شركت كنند گان در بزوهش حاضر بسر بودند كه در سه گروه اسكيزوتايبى بالا 19 (F/F/FF)، هايبومانى ها ها ( 1 (

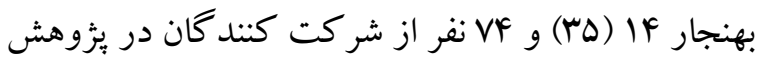
حاضر دختر بودند كه در سه گروه اسكيزوتاييى بالا

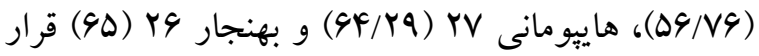

جدول ץ نتايج يافتههاى توصيفى، آزمون تحليل واريانس يك طرفه و آزمون حداقل اختلاف معنىدار به تفكيك كروهها

\begin{tabular}{|c|c|c|c|c|c|c|c|c|c|c|}
\hline \multirow{2}{*}{ 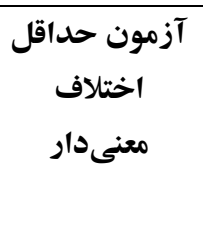 } & \multirow[t]{2}{*}{ سطح معنى } & \multirow[t]{2}{*}{$\mathbf{F}$} & \multicolumn{2}{|c|}{$\begin{array}{c}\text { بهنجار } \\
\text { (N) }\end{array}$} & \multicolumn{2}{|c|}{$\begin{array}{c}\text { هايِومانى } \\
\text { (H) }\end{array}$} & \multicolumn{2}{|c|}{$\begin{array}{c}\text { اسكيزوتاييى بالا } \\
\text { (S) }\end{array}$} & & \multirow[t]{2}{*}{ آزمون } \\
\hline & & & انحراف & ميانگين & انحراف & ميانكين & انحر اف & ميانكين & & \\
\hline $\mathrm{H}>\mathrm{S}>\mathrm{N}$ &.$/ . \cdot 1$ & $\Delta / V$ & $\Delta / 1$ & r9/9 & $r / \Delta$ & $4 \cdot 10$ & $9 / 4$ & $r V / r$ & سيالى س & خلاقيت عابدى \\
\hline $\mathrm{H}>\mathrm{N}$ &.$/ \cdot 11$ & $F / r$ & $r / v$ & $r Y / r$ & $r / 1$ & $r \Delta / q$ & f & $r Y / V$ & انعطاف & \\
\hline $\mathrm{H}>\mathrm{S}>\mathrm{N}$ & $\cdot / \cdot \cdot 1$ & $V / 9$ & $\mathrm{~V} / \mathrm{V}$ & $19 / 9$ & $F / V$ & $\Delta r / \Lambda$ & $V / \Delta$ & $F_{N / q}$ & ابتكار & \\
\hline - & $\cdot / \cdot v$ & $1 / 1$ & $r / \Lambda$ & $r q / 4$ & r & $r q / r$ & $r / r$ & $r q / 9$ & بسط & \\
\hline $\mathrm{S}>\mathrm{H}>\mathrm{N}$ & .1 .19 & $\Delta / r$ & $F / N$ & $1 r / \Delta$ & $F / r$ & $|f /|$ & $r / f$ & $19 / \pi$ & سيالى ل & تفكر خلاق تورنس \\
\hline $\mathrm{H}>\mathrm{S}>\mathrm{N}$ & $\cdot / \cdot \Delta$ & $r / f$ & $r / 9$ & $11 / 9$ & $r / \Lambda$ & $\mid r / 1$ & $r / \Delta$ & $1 r / 4$ & انعطاف & Bرم B \\
\hline
\end{tabular}




\begin{tabular}{|c|c|c|c|c|c|c|c|c|c|}
\hline $\mathrm{S}, \mathrm{H}>\mathrm{N}$ &.$/ . \mathrm{Fr}$ & $r / q$ & $\Lambda / 9$ & $I V / \Delta$ & $11 / 1$ & $Y Y / Y$ & $9 / r$ & $r) / 9$ & ابتكار \\
\hline $\mathrm{S}, \mathrm{H}>\mathrm{N}$ &.$/ . \cdot 1$ & $11 / \mathrm{V}$ & YF/A & $\Lambda V / \Lambda$ & YN/G & $a r / r$ & $r \varepsilon / r$. & $91 / 1$ & بسط \\
\hline $\mathrm{S}>\mathrm{H}>\mathrm{N}$ &.$/ . \cdot 1$ & $9 / 1$ & rG/A & $V \wedge / \Delta$ & YG/9 & $\Lambda r / \Lambda$ & $r V / F$ & $19 / 9$ & - \\
\hline
\end{tabular}

تكليف تصوير سازى
افراد بهنجار است. نتايج همجينين نشان داد كه نمره كلى خلاقيت در گروه هايبومانيك بيشتر از اسكيزوتايبى بالاو در كروه اسكيزوتاييى بالا بيشتر از افراد بهنجار است.

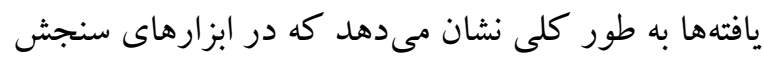
خلاقيت افراد گروه هاييومانى و اسكيزوتاييى بالا (افراد مستعد سايكوز) نمرات بيشترى از افراد بهنجار به دست مى آورند.

بحث هدف از ئزوهش حاضر مقايسه خلاقيت در افراد مستعد سايكوز (هاييومانيكك و اسكيزوتايبى بالا) با افراد بهنجار بود. نتايج اين يثوهش نشان داد كه نمرات يرسشنامه خلاقيت عابدى در كروه هاييومانيك بيشتر از كروه اسكيزوتايبى بالا و بهنجار است. اين يافته با نتايج بثوهش لتش

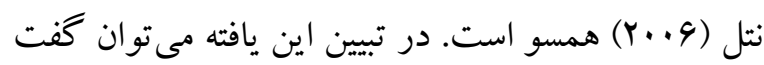
عاطفه مثبت فرايند تفكر خلاق را تسهيل مى كنند و از آنجايى كه در مرحله غربال گرى با استفاده از فهرست وارسى علائم تجديد نظر شده اضطراب) كنترل شد، بنابراين افراد هاييومانيك داراى خصيصه برجسته فعاليت/ شادكامى خلاقيت بيشترى كزارش كردند. يافتهاى بُزوهش حاضر نشان داد كه نمرات خلاقيت در ابزارهاى تفكر خلاق (فرم ب خلاقيت تورنس) و تكليف تصويرسازى در كروه اسكيزوتاييى بيشتر از كروه

\footnotetext{
${ }^{46}$ - Symptom Checklist-90-Revised
}

با توجه به نتايج ارائه شده در جدول Y، ميزان F براى مؤلفهاى سيالى، انعطاف و ابتكار در برسشنامه خلاقيت عابدى و مؤلفههاى سيالى، انعطاف، ابتكار و بسط در آزمون تفكر خلاق تورنس فرم B و تكليف تصوير سازى و خلاقيت كلى معنادار است (ه) (P) و و كروههاى مورد بررسى در متغيرهاى مورد نظر با همديخر تفاوت معنادارى دارند. در حالى كه در مؤلفه بسط بين سه كروه در برسشنامه خلاقيت عابدى تفاوت معنىدارى يافت نشد (ه>•/P>). نتايج حاصل از آزمون حداقل اختلاف معنىدار نشان مىدهد كه در مؤلفهاى سيالى و ابتكار در برسشنامه خلاقيت عابدى نمرات افراد در گروه

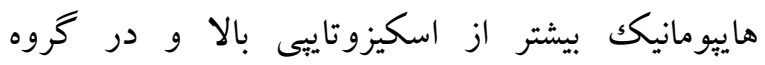
اسكيزوتاييى بالا بيشتر از افراد بهنجار است. در مؤلفه انعطاف نمرات گروه هاييومانيك بيشتر از افراد بهنجار است. همجينين در آزمون تفكر خلاق تورنس فرم B نمره كروه اسكيزوتاييى بالا در مؤلفه سيالى بيشتر از هايبومانيك و در گروه هاييومانيكك بيشتر از افراد بهنجار است در حالى كه در مؤلفه انعطاف در اين آزمون نمره كروه هاييومانيك بيشتر از اسكيزوتاييى بالا و در كروه اسكيزوتاييى بالا بيشتر از افراد بهنجار است، در مؤلفههاى

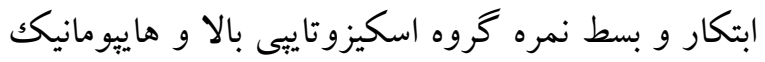
بيشتر از افراد بهنجار است در حالى كه بين نمرات اين دو كروه تفاوتى يافت نشد. در تكليف تصوير سازى با حروف لاتين نمره افراد خروه اسكيزوتاييى بالا بيشتر از افراد كروه هاييومانيك و در خروه هاييومانيك بيشتر از 


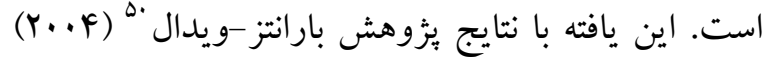
مبنى بر اينكه تفكر خلاق در هاييومانى بيشتر از اسكيزوتاييى است و تفكر خلاق بيشتر با برش افكار در مانيا ارتباط دارد تا با شل شدن تداعىها در اسكيزوفرنى و

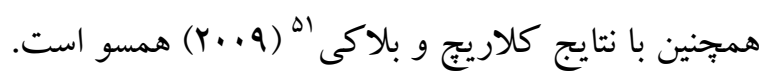
يافتهاى بثزوهش حاضر همجنين حاكى از آن است كه خلاقيت در افراد هايِومانيك بيشتر از افراد بهنجار است.

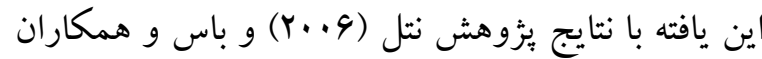

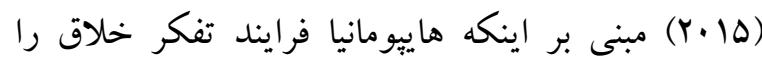
تسهيل مى كند، همسو است. در تبيين اين يافته مىتوان

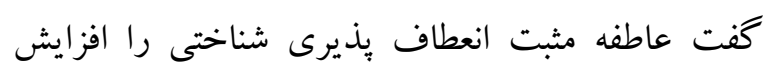
مىدهد و به همين ترتيب فعاليتهاى خلاق را تسهيل

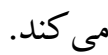
يافتهاى اين يُوهش هم:جنين نشان مىدهد كه خلاقيت در افراد داراى اسكيزوتاييى بالا بيشتر از افراد بهنجار

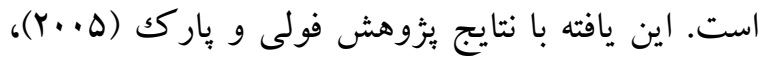

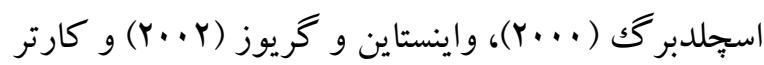
(Y.10) همسو است. در تبيين اين يافته مىتوان كفتت افراد داراى اسكيزوتايبى به واسطه تجارب ادراكى غير معمول و گفتار و رفتار عجيب و غريب تجاربى داشتهاند كه متفاوت از افراد عادى بوده است (عاشورى و

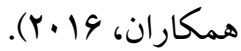

\section{نتيجه كيرى}

در مجموع با استناد به اين يافته ها مىتوان كفت مناقشه

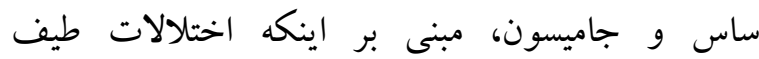
اسكيزوفرنيا و اختلالات طيف دو قطبى با خلاقيت ارتباط دارند، هر دو درست به نظر مىرسد و شواهدى در تائيد

${ }^{50}$ - Barrantes-Vidal

${ }^{51}$ - Claridge\&Blakey
هاييومانيك و گرووه بهنجار است. اين يافته با نتايج

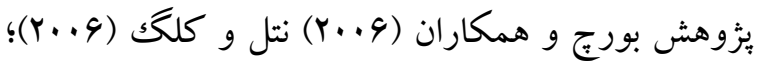

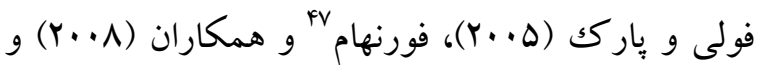

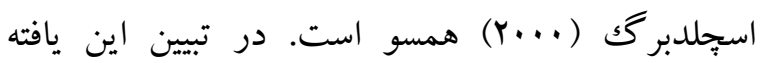
مىتوان كفت خلاقيت با نيمكره راست ارتباط دارد و جون افراد اسكيزوتاييال در بردازش نيمكرهها عدم تقارن دارند و نيمكره راست در آنها برترى دارد (فيشر ^^و و

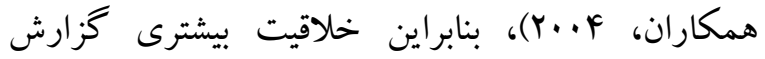
مى كنند؛ به عبارت ديخر سو گيرى نيمكرهاى ممكن است عامل سست شدن تداعىها "qه در اين افراد باشد و اتصال غير معمول عقايد به هم كه توسط فعاليت نيمكره راست تسهيل مى شود، ممكن است قسمتى از فرايند تفكر خلاق باشد (فيشر و همكاران، F. . F) اين يافتهاى به طور كلى نشان مىدهد كه اسكيزوتاييى بيشتر با تكاليف خلاقيت به ويزه فرم ب خلاقيت تورنس و تكليف تصوير سازى ارتباط دارد درحالى كه هاييومانى بيشتر با ابزارهاى خود گز ارشى (يرسشنامه خلاقيت عابدى) ارتباط دارد. در تبيين اين يافته مىتوان كفت افراد اسكيزوتايبى به تكاليف ترسيم اشكال و تصوير سازى بدون بازدارى ياسخ مىدهند در حالى كه نسبت به ابزارهاى خود گزارشى بازدارى نشان مىدهند. همجينين به علت عدم تقارن نيمكرهها و برترى نيمكره راست، نمرات بيشترى را در تكاليف خلاقيت كه مستقيماً با عملكرد نيمكره راست در ارتباط است، كسب مى كنند (فيشر و

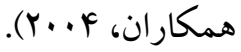
يافتهاى يُزوهش حاضر نشان داد كه خلاقيت در افراد

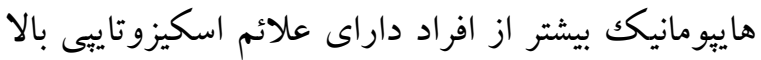

\footnotetext{
47- Furnham

${ }^{48}$ - Fisher

${ }^{49}$ - loss of association
} 
Barrantes-Vidal N. (2004). Creativity \& Madness Revisited form Current Psychological Perspectives. Journal of consciousness Studies, $11(3-4), 58-78$.

Bass M, Nijstad BA, Boot NC, \& De Dreu CKW. (2016). Mad genius revisited: Vulnerability to psychopathology, biobehavioral approachavoidance, and creativity. Psychological bulletin, 142 (6), 668-692.

Brod J. (1997). Creativity and schizotypy. IN: Claridge GS, Editors. Schizotypy: Implications for illnessand health. New York: Oxford University Press, 276-298.

Burch G, Pavelis C, Hemsley D, \& Corr P. (2006). Schizotypy and creativity in visual rtists. British Joumal Psychology, 97(2), 177-190.

Carter C. (2015). The relationship between cognitive inhibition, mental illness, and creativity. Theses and Dissertations. 263.

Claridge G, \& Blakey S. (2009). Schizotypy and affective temperament: Relationships with divergent thinking andcreativity styles. Personality and Individual Differences, 46 (8), 820-826.

Daemi H, and Moghimi F. (2004). Normalization of The Creativity Test. Advances in Cognitive Science, 6(3-4), 1-8. (Persian)

Durrenberger SD. (1999). Mad genius controversy. IN: Runco MA, Pritzker S, Editors. The Encyclopedia of creativity, Volume 2. San Diego: Academic Press, 169-177.

Eysenck H. (1995). Genius: The Natural History of Creativity. Cambridhe UK: Cambridge University Press, 278-310.

Fisher JE, Mohanty A, Herrington JD, Koven NS, Miller GA, \& Heller W. (2004). Neuropsychologicalevidence for dimensional schizotypy:Implication for creativity andpsychopathology. Joumal of Research in Personality, 38 (1), 24-31.

Folley BS, \& Park S. (2005). Verbal creativity and schizotypal personality in relation to prefrontal hemispheric laterality: A behavioral and nearinfrared optical imaging study. Schizophrenia Research, 80(2-3), 271-282.

$$
\begin{aligned}
& \text { ارتباط U وارونه خلاقيت با آسيب شناسى روانى است } \\
& \text { كه اين ارتباط نيز در بسيارى از يزوهشها تأييد شده }
\end{aligned}
$$

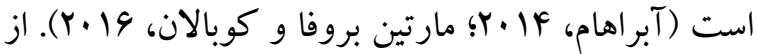

$$
\begin{aligned}
& \text { محدوديتهاى يثزوهش حاضر استفاده نمونه غربال گرى } \\
& \text { شده است، بنابراين تعميم نتايج به نمونهاى بالينى را } \\
& \text { محدود مىسازد. بيشنهاد مىشود بيزوهشهاى آتى به } \\
& \text { بررسى اين ارتباط در نمونهاى بالينى و همجِنين } \\
& \text { خويشاوندان درجه يكك بيماران دوقطبى و اسكيزوفرنى } \\
& \text { صورت گيرد. } \\
& \text { سباسگز ارى } \\
& \text { بدينوسيله از تمامى دانشجويانى كه در اجراى اين } \\
& \text { بثزوهش ما را يارى كردند تقدير و تشكر مى گردد. }
\end{aligned}
$$

\section{References}

Abraham A. (2014). Is there an inverted-U relationship between creativity and psychopathology? Frontiers in Psychology, 5,750: 1-2.

Akiskal H, \& Akiskal P. (1988). Reassessing the significance of bipolar disorders:Clinical significance and artistic creativity. Psychiatry and Psychobiology, 3(2), 29-36.

Akiskal H. (1983). The bipolar spectrum: New concepts in classification and diagnosis. $\mathbb{N}$ : Grinspoon L, Editors. Psychiatry update: The American psychiatric association annual review, Volume II. Washington, DC: American Psychiatric Press, 271-292.

Andreasen N. (1987). Creativity and Mental Illness: Prevalence rates in writers and their firstdegree relatives. American Joumal Psychiatry, 144(10), 1288-1292.

Ashouri A, Mohammadzadeh A, Najafi N, Zeraatkar L. (2016). Relationship Between Personality Traits and Religious/Spiritual Well-Being With Schizotypal Traits. Iranian Journal of Psychiatry and Clinical Psychology, 22(3),230-239. (Persian) 
Forty L, Kelly M, Jones L, Jones I, Barnes E, Caesar S, Fraser C, Gordon-Smith K, Griffiths E, Craddock N, \& Smith DJ. (2010). Reducing the Hypomania Checklist (HCL-32) to a 16item version. Joumal of Affective Disorders, 124(3), 351-356.

Fumham A, Batey M, Anand K, \& Manfield J. (2008). Personality, hypomania, intelligence and creativity. Personality and Individual Differences, 44 (5), 1060-1069.

Jamison K. (1989). Mood disorders and pattems of creativity in British writersand artists. Psychiatry, 52 (2), 125-134.

Jamison K. (2001). Reply to Louis A. Sass: "Schizophrenia, Modemism, and the "Creative Imagination". Creativity Research Journal, 13(1), 75-76.

Kyaga S, Lichtenstein P, Boman M, Hultman C, Langstrom N, \& Landen M. (2011). Creativity and mental disorder. family study of 300,000 people with severe mental disorder. British jourmal Psychiatry, 199(5), 373-379.

Martin-Brufau R, \& Corbalan J. (2016). Creativity and psychopathology: Sex matters. Creativity research joumal, 28 (2), 222-228.

Nettle D, Clegg H. (2006). Schizotypy, creativity, and mating successin humans. proceedings of the royal society b biological sciences. 273 (1586), 611-615.

Nettle D. (2006). Schizotypy and mental health amongst poets, visual artists andmathematicians. Joumal of Research in Personality, 40 (6), 876-890.

Nowakowska C, Strong C, Santosa C, Wang P, \& et al. (2005).Temperamental commonalities and differences in euthymic mood disorderpatients, creative controls and healthy controls. Joumal of Affective Disorders, 85 (12), 207-215.

Raine A, Reynolds C, Lencz T, Scerbo A, \& et al. (1994). Cognitive-perceptual, interpersonal, and disorganized features of schizotypalpersonality. Schizophrenia Bulletin, 20 (1), 191-201.

Raine A. (1991). The SPQ: a scale for the assessment of schizotypal personalitybased on DSM-III-R criteria. Schizophrenia Bulletin, 17(4), 555564.

Richards R, Kinney D, Lunde I, \& Benet M. (1988). Creativity in manic-depressives, cyclothymiacs, and their normal First-degree relatives: A preliminaryreport. Joumal of Abnormal Psychology, 97(3), 281-288.

Santosa C, Strong C, Nowakowska C, Wang P, \& et al. (2007). Enhanced creativity in bipolar disorder patients: A controlledstudy. Journal of Affective Disorders, $100(1-3), 31-39$.

Sass L. (2001). Schizophrenia, modemism, and the 'creative imagination': on creativity and psychopathology. Creativity Research Journal, $13(1), 55-74$.

Schuldberg D. (2000). Six subclinical spectrum traits in normal Creativity. Creativity Research Joumal, 13(1), 5-16.

Simonton DK. (2014). More method in the madgenius controversy: a historiometric study of 204 hostoric creators. Psychology of Aesthetics, Creativity and the Arts, 8(1), 53-61.

Stemberg RJ. (2001). Teaching psychology students that creativity is a decision. The General Psychologist, 36(1), 8-11.

Strong C, Nowakowska C, Santosa C, Wang P, \& et al. (2007). Temperament-creativity relationships in mood disorder patients, healthy controls and highly creative individuals. Joumal of Affective Disorders,100(1-3),41-48.

Torrance EP. (1988). The nature of creativity as manifest in its testing. IN: Sternberg RJ Editors. The nature of creativity: Contemporary psychological perspectives, Volume I. New York: Cambridge University Press, 43-75.

Weinstein S, Graves R. (2002). Are creativity and schizotypy products of a right hemisphere bias? Brain and Cognation, 49 (1), 138-151. 